\title{
Oromucosal/Laryngopharyngeal Solution Dosage Form
}

National Cancer Institute

\section{Source}

National Cancer Institute. Oromucosal/Laryngopharyngeal Solution Dosage Form. NCI

Thesaurus. Code C149745.

Liquid preparation consisting of a solution intended for oromucosal or laryng opharyngeal use. 